\title{
SISTEM KULIAH PORTOFOLIO (SKUP) MAHASISWA BERBASIS ILEARNING MEDIA (IME) PADA PERGURUAN TINGGI
}

\author{
Untung Rahardja ${ }^{1}$ \\ Qurotul Aini ${ }^{2}$ \\ Femi Allamiah ${ }^{3}$ \\ Dosen STMIK Raharja ${ }^{1,2}$ \\ STMIK Raharja Jurusan Sistem Informasi ${ }^{3}$ \\ Jl. Jendral Sudirman No. 40, Modernland, Tangerang \\ Email: untung@raharja.info ${ }^{1}$, aini@raharja.info ${ }^{2}$,emi@raharja.info ${ }^{3}$
}

\begin{abstract}
ABSTRAK
Dengan adanya perkembangan Teknologi Informasi yang semakin pesat didunia pendidikan memerlukan media informasi sebagai proses belajar mengajar. Metode pembelajaran yang mudah merupakan cara yang digunakan dosen untuk mencapai suatu tujuan pembelajaran yang bertujuan untuk meningkatkan kemampuan serta kemandirian mahasiswa dalam pembelajaran di kelas menggunakan iLearning Media(iMe) Class Meskipun sudah banyak macam metode pembelajaran didunia pendidikan, namun menggunakan iMe cukup efektif praktis mudah dan sangat baik untuk menunjang proses belajar dan mengajar terutama pada mahasiswa iLearning di Perguruan Tinggi Raharja yang proses belajar mengajarnya menggunakan device yaitu iPad di Perguruan Tinggi Raharja. Dan yang lebih menariknya lagi didalam iLearning Media(iMe) Class terdapat portofolio yang memudahkan Mahasiswa dalam menyimpan tugas mereka tanpa takut kehilangan berkas yang terjadi saat pengumpulan tugas yaitu dengan membuat Sistem Kuliah Portofolio (SKUP) di dalam iLearning Media(iMe) Class . Yang menjadi kendala saat ini adalah masih banyak para mahasiswa yang belum mempergunakan metode pendidikan yang berteknologi informasi modern saat ini. Untuk mengatasi masalah seperti yang dijelaskan, dapat dilakukan dengan menggunakan metode pembelajaran untuk menunjang kegiatan belajar mengajar dengan menggunakan iLearning Media(iMe) Class dan menyimpan tugas pada Sistem Kuliah Portofolio $(S K U P)$. Maka diperlukan proses yang cepat dan efisien agar dapat menyelesaikan masalah yang terjadi . Saat ini proses belajar mengajar hanya sekedar duduk dan mendengarkan dosen yang sedang menjelaskan didepan serta mengerjakan tugas secara manual, tanpa diketahui mahasiswa tersebut mengerti atau tidak dengan yang dijelaskan oleh dosen bahkan mahasiswa tidak mandiri dalam mengerjakan tugas yang diberikan.
\end{abstract}

Kata Kunci : iMe (iLearning Media)

\section{ABSTRACT}

The development of Information Technology, which grew rapidly in the world of education requires information media as a learning process. Easy learning method is the way in which the lecturer to achieve a goal of learning which aims to improve the capability and independence of the students are iLearning Media (iMe). Although many kinds of learning methods in education world, yet effective enough practical use IME easy and very good to support the teaching and learning process, especially at the iLearning students in Higher Education Prog the teaching and learning process using a device that is the iPad in Higher Education Prog. And more interesting again in iLearning Media (iMe) are portfolios that facilitate students to store their duties without fear of losing files that occurs when the task is to create a collection Class Portfolio System (SKUP) in iLearning Media (iMe). Which became the current constraints are still many students who do not use methods of modern information technology education 
today. To solve the problem as described, can be performed using the method of learning to support teaching and learning activities using iLearning Media (iMe) and save tasks on the System Class Portfolio (SKUP). It is necessary to process quickly and efficiently in order to solve problems that occur. Currently the learning process just sitting and listening to a lecturer who was explaining ahead and do the work manually, without the knowledge of the student understands or not to that described by professors and even students are not self-sufficient in a given task.

Keyword: iMe (iLearning Media)

\section{PENDAHULUAN}

Metode pembelajaran saat ini merupakan cara yang digunakan dosen untuk mencapai tujuan pembelajaran. Suatu metode yang dapat digunakan oleh dosen dalam proses pembelajaran yang bertujuan untuk meningkatkan kemampuan dan kemandirian peserta didik yakni membuat Sistem Kuliah Portofolio (SKUP). Metode pembuatan Sistem Kuliah Portofolio $(S K U P)$. Namun setiap metode pembelajaran yang telah diberikan tentunya ada kelebihan atau kelemahannya, Para Mahasiswa pun kini sudah sangat mudah dalam menyimpan suatu tugas perkuliahan dengan aman dan efektif tanpa harus merasa khawatir akan terjadi kehilangan tugas yang sudah diberikan kepada dosen. Dosen pun sangat mudah mengakses dan melihat tugas para Mahasiswa/i dengan mudah dengan melihat Sistem Kuliah Portofolio (SKUP) yang sudah Mahasiswa/i telah buat pada iLearning Media(iMe) Class. Metode pembelajaran yang dilakukan diharapkan mampu meningkatkan kemampuan peserta didik untuk lebih mandiri dalam proses berpikir untuk menganalisa suatu persoalan.

Pada perkembangan era globalisasi dan teknologi yang semakin canggih saat ini. Dalam dunia pendidikan memerlukan media yang efektif untuk proses belajar mengajar, yang bisa memberikan kemajuan pada semua aspek yang berhubungan dengan informasi salah satu perkembangan teknologi tersebut adalah iLearning Media(iMe) Class, maka dari itu untuk mempermudah suatu proses pembelajaran dengan adanya Sistem Kuliah Portofolio (SKUP) didalam iLearning Media(iMe) Class . sangat membantu dalam proses belajar mengajar. Inovasi tersebut telah diterapkan oleh Perguruan Tinggi Raharja. Dimana metode ini berkaitan dengan 4B (Belajar,Bekerja,Bermain,Berdoa). Dalam metode iLearning tersebut terdapat 10 (sepuluh) pilar dan salah satunya adalah iLearning Media(iMe) didalam website tersebut mahasiswa bisa melaporkan tugasnya pada Sistem Kuliah Portofolio (SKUP) .dengan cara mengirim istilah ini muncul dari pemikiran Ir Untung Rahardja, M.T.I pada tahun 2009. iLearning Media(iMe) adalah suatu site pembelajaran secara online yang merupakan media publikasi yang telah disediakan oleh Perguruan Tinggi Raharja sebagai tempat wawasan aktifitas/kegiatan yang menjadi pokok berbagi informasi atau menyimpan data.

Metode iLearning dimana iLearning Media(iMe) Class . dibuat untuk meningkatkan kemandirian Mahasiswa. Karena untuk mendaftar iLearning Media(iMe) Class, dibutuhkan pendaftaran (register) menggunakan email Rinfo. Rinfo (Email raharja.Info) merupakan alat komunikasi email paling vital yang telah disediakan oleh Perguruan Tinggi Raharja untuk semua Pribadi Raharja.

Walaupun sudah banyak sekali media pembelajaran untuk kegiatan proses belajar mengajar, Maka sebuah wadah pembelajaran yang menggunakan iLearning Media(iMe) Class cukup efektif dan efisien, sehingga sangat baik untuk menunjang proses belajar dan mengajar terutama pada mahasiswa/i iLearning yang sudah makin mudah dalam penyimpanan tugas 
dengan Sistem Kuliah Portofolio (SKUP) yang proses pembelajarannya berbasis device yaitu iPad.

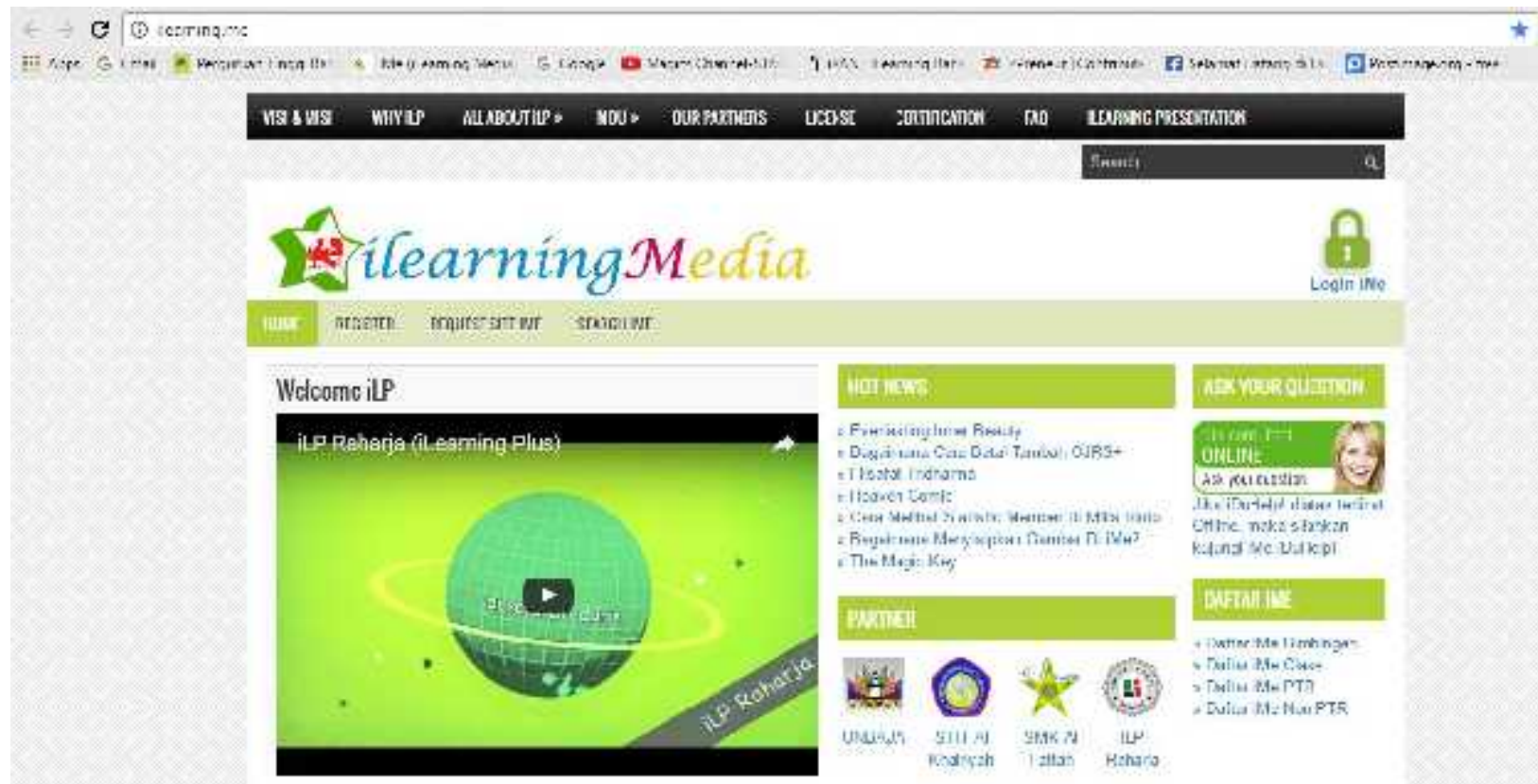

Gambar 1. Pada gambar 1. Merupakan halaman utama pada iLearning Media(iMe).

Proses belajar mengajar adalah inti aktivitas dalam pendidikan. Proses ini merupakan media penyimpanan publikasi tugas/segala aktifitas mahasiswa/i yang bisa dilihat kapanpun oleh dosen dan mahasiswa/i. Seiring dengan berkembangannya era globalisasi yang semakin pesat di dunia Teknologi Informasi dan Komunikasi (TIK). Tentunya didalam penggunaan metode proses belajar mengajar Perguruan Tinggi Raharja yang menerapkan konsep IT yang memerlukan suatu sarana dan prasarana TIK yang up to date untuk menunjang kegiatan Tri Dharma, sehingga dapat menjawab tantangan yang ada, khususnya untuk meningkatkan kualitas proses belajar mengajar yang lebih mudah. Salah satu sarana untuk menunjang proses belajar mengajar yaitu dengan konsep iLearning. iLearning memanfaatkan teknologi internet sebagai sarana penyajian dan distribusi informasi. Karena berbasis teknologi internet sehingga media pembelajaran iLearning dapat diakses dari manapun selama tersedia akses pada internet.

Menurut Femi Allamiah media ini merupakan media publikasi online yang membuat tugas atau pun sekedar hanya sharing cerita tanpa adanya tatap muka langsung antar mahasiswa/i dengan dosen. Sementara itu implementasi dari media publikasi ini dapat digunakan untuk memudahkan mahasiswa/i dan memberikan solusi terhadap permasalahan yang sedang berjalan dalam proses belajar mengajar yang sangat terbatas pada masalah tempat penyimpanan tugas yang lebih efektif dan mudah disimpan didalam Sistem Kuliah Portofolio (SKUP) yang ada pada iLearning Media(iMe) Class .

\section{PERMASALAHAN}

Dalam satu semester setiap dosen memberikan suatu tugas kepada mahasiswa/i, baik tugas kelompok maupun individu. Biasanya mahasiswa/i tidak tahu apakah tugas yang sudah 
dikumpulkan kepada dosen sudah tersimpan atau hilang, sehingga ada sedikit rasa kekhawatiran. Karena itu tidak sedikit mahasiswa/i tidak peduli dengan tugas tersebut dan akan muncul ketidak disiplinan. Pada hal ini rasa malas pun bisa tak terkendali, sehingga para mahasiswa/i mengulur waktu dalam pengumpulan tugas yang diberikan dosen, yang seharusnya dikumpulkan pada waktu yang sudah ditentukan oleh dosen.

Karena ini para dosen tidak mengetahui secara rinci assignment dan profil mahasiswa/i secara singkat dan mudah dicari. Dengan berkembangnya suatu era globalisasi dimana para mahasiswa/i pun bisa berbuat curang pada tugas, seperti menjiplak punya teman atau plagiat. Dengan begitu bisa jadi dosen tersebut hanya memeriksa dan tidak membacanya. Tugas perkuliahan pun hanya bisa tersimpan dan tidak bisa dilihat kapanpun dengan mudah. Namun jika ada pembelajaran di semester berikutnya, mau tidak mau tugas perkuliahan itu harus dicari ditempat penyimpanan, dan banyak assignment mahasiswa/i banyak yang hilang atau terselip tidak rapih. Sehingga menyulitkan dosen dan mahasiswa/i dalam pembelajaran maupun penilaian seperti dalam pembelajaran mahasiswa/i harus bertatap muka dengan dosen. Selain itu assignment tidak dapat tersusun dan tidak terdokumentasi dengan baik.

Dalam suatu penyimpanan tugas perkuliahan mahasiswa/i dituntut untuk selalu mengumpulkan tugas yang sudah mereka kerjakan . tetapi saat tugas perkulihan mahasiswa/i sudah diberikan kepada dosen melalui iLearning Media(iMe) Class . Terkadang tugas tersebut tidak rapih dan tidak ada wadah penyimpanan tugas yang mudah ditemukan oleh dosen .

Dengan adanya Sistem Kuliah Portofolio (SKUP) permasalahan yang ada saat penyimpanan tugas-tugas tidak tercecer atau hilang begitu saja saat pengumpulan tugas kepada dosen, dan terdata rapih sehingga mahasiswa/i atau dosen pun mudah untuk mencari tugas yang sudah dikerjakan. Jika sebelumnya tugas hanya disimpan pada iLearning Media(iMe) Class saja itu tidak membuat tugas terlihat tersusun dengan rapih karena dosen akan sulit mencari tugas yang mana saja yang sudah dikoreksi . Maka dari itu dengan adanya Sistem Kuliah Portofolio $(S K U P)$ ini semua tugas menjadi tersusun dengan rapih dan mudah ditemukan oleh mahasiswa/i atau dosen tersebut .

Apabila di era informasi dan komunikasi ini kita memanfaatkan teknologi yang semakin canggih walaupun ada sisi negatif serta positif didalam teknologi tersebut yang bisa diterima oleh para mahasiswa/i agar semakin berkembang. Dalam masalah ini pun mahasiswa/i mempunyai masalah yang takut akan mengungkapkan sesuatu hal.

Efektifitas Kecanggihan yang kini telah masuk kedalam dunia pendidikan diterima postif oleh para mahasiswa/i yang selama ini terbatas oleh ruang dan waktu yakni dengan menggunakan iLearning Media(iMe) Class. Namun pada media publikasi tersebut masih ada sedikit kekurangan, seperti mahasiswa/i plagiat tugas dari mahasiswa/i yang lain dan tidak tahu siapa saja yang melihat website yang dimiliki oleh para mahasiswa/i. Dari masalah tersebut mahasiswa/i menjadi malas mengerjakan tugas yang diberikan dosen, tidak bersemangat dan berkurangnya konsentrasi pada Mahasiswa/i. Mahasiswa/i pun terkadang kesulitan untuk mengakses media tersebut terkadang terkendala pada jaringan internet atapun website tersebut sedang mangalami error. Untuk mengatasi masalah tersebut sebuah media publikasi atau penyimpanan data dan pembelajaran secara online yang menghadirkan iLearning Media(iMe) Class. 


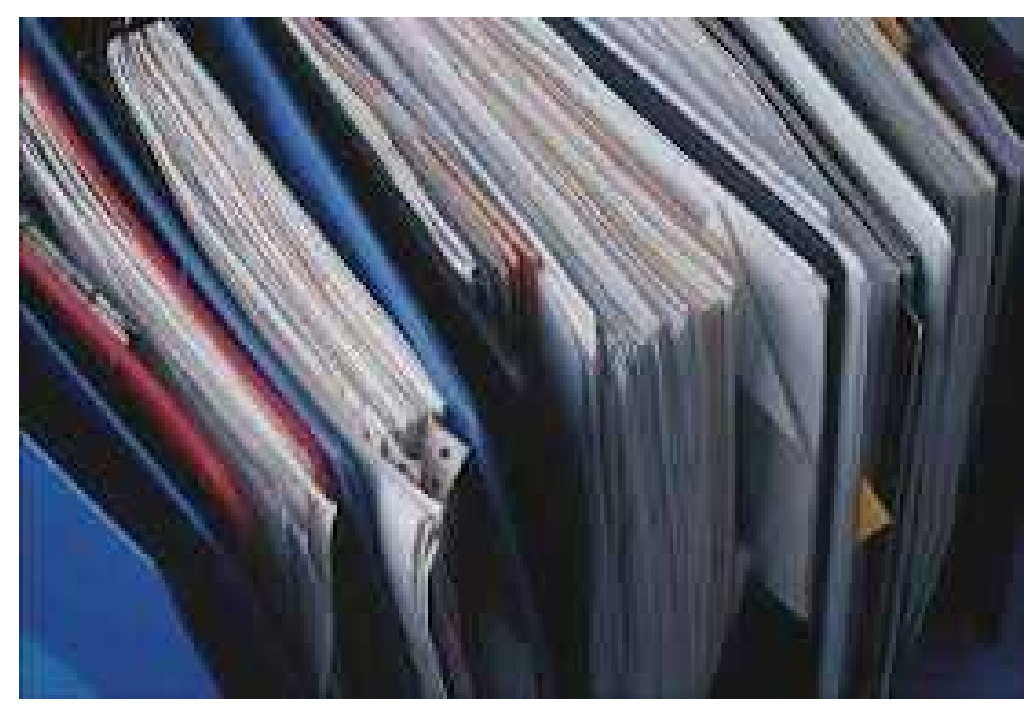

Gambar 2 diatas merupakan contoh dari penyimpanan Tugas para mahasiswa/i yang tidak tertata rapih

Dari pembahasan diatas, dapat dirumuskan satu permasalahan yaitu :

1. Apakah Sistem Kuliah Portofolio (SKUP) dapat membantu mahasiswa/i agar lebih disiplin dalam menyimpan tugasnya dengan tertata rapih didalam Sistem Kuliah Portofolio (SKUP) ?

\section{LITERATURE REVIEW}

Metode study pustaka dilakukan untuk menunjang metode wawancara dan observasi yang telah dilakukan. Pengumpulan informasi yang dibutuhkan dalam mencari referensi-referensi yang berhubungan dengan penelitian yang dilakukan.

Manfaat dari study pustaka (Literature Review) ini antara lain :

1. Mengidentifikasikan kesenjangan (identify gaps) dari penelitian ini.

2. Menghindari membuat ulang (reinventing the wheel) sehingga banyak menghemat waktu dan juga menghindari kesalahan- kesalahan yang pernah dilakukan oleh orang lain.

3. Mengidentifikasikan metode yang pernah dilakukan dan yang relevan terhadap penelitian ini.

4. Meneruskan apa yang penelitian sebelumnya telah dicapai sehingga dengan adanya studi pustaka ini, penelitian yang akan dilakukan dapat membangun di atas landasan (platform) dari pengetahuan atau ide yang sudah ada.

Banyak penelitian yang sebelumnya dilakukan mengenai penerimaan mahasiswa baru secara online dan penelitian lain yang berkaitan. Dalam upaya mengembangkan dan menyempurnakan penerimaan mahasiswa baru secara online ini perlu dilakukan studi pustaka (literature review) sebagai salah satu dari penerapan metode penelitian yang akan dilakukan. Diantaranya yaitu:

1. Penelitian yang dilakukan oleh Lorraine Stefani, Robin Mason \& Chris Pegler dari Routledge yang berjudul "The Educational Potential of e-Portfolios: supporting personal development and reflective learning" tahun 2007. Penelitian ini membahas tentang potensi e-portfolio dalam pendidikan dengan sejumlah pendukung studi kasus dan sejumlah besar sumber daya online yang berguna dari Inggris dan di seluruh dunia. Ini adalah buku panduan praktis untuk membantu mereka yang tertarik dalam e-portfolio untuk belajar dan mengajar. 
Buku ini disusun dalam cara mengambil pembaca melalui tahapan e-portfolio implementasi yang akan diterapkan ke terbaru dari pengguna. Tema-tema mengikuti urutan logis dan memiliki fluiditas yang konsisten antara bab. Ini menyoroti kompleksitas dan masalah potensial pengguna mungkin menghadapi ketika menerapkan e-portfolio, sementara secara bersamaan mengidentifikasi keuntungan dan manfaat potensial untuk belajar dan mengajar yang dapat dialami dengan menggunakan e-portfolio

2. Penelitian yang dilakukan oleh Lorraine Stefani, Robin Mason \& Chris Pegler dari Routledge yang berjudul "The Educational Potential of e-Portfolios: supporting personal development and reflective learning" tahun 2007. Penelitian ini membahas tentang potensi e-portfolio dalam pendidikan dengan sejumlah pendukung studi kasus dan sejumlah besar sumber daya online yang berguna dari Inggris dan di seluruh dunia. Ini adalah buku panduan praktis untuk membantu mereka yang tertarik dalam e-portfolio untuk belajar dan mengajar. Buku ini disusun dalam cara mengambil pembaca melalui tahapan e-portfolio implementasi yang akan diterapkan ke terbaru dari pengguna. Tema-tema mengikuti urutan logis dan memiliki fluiditas yang konsisten antara bab. Ini menyoroti kompleksitas dan masalah potensial pengguna mungkin menghadapi ketika menerapkan e-portfolio, sementara secara bersamaan mengidentifikasi keuntungan dan manfaat potensial untuk belajar dan mengajar yang dapat dialami dengan menggunakan e-portfolio.

3. Penelitian yang dilakukan oleh Ellen R. Cohn and Bernard J. Hibbitts dari University of Pittsburgh yang berjudul "Beyond the Electronic Portfolio: A Lifetime Personal Web Space" tahun 2004. Penelitian ini membahas tentang portofolio elektronik (e-portfolio) adalah pendidikan tinggi yang baru "harus memilikinya" alat-acara-dan-kirim platform milenium. Ratusan lembaga akademik berbagai mempelajari, menggunakan, atau e-portofolio inovasi sistem. Memang, gerakan e-portfolio saat ini pemindahan komite universitas baru, modul pelatihan di kampus, buku, kampus-lebar kampanye informasi, pekerjaan, dan industri berpotensi menguntungkan bagi perusahaan perangkat lunak dan konsultan. Selain itu, fakultas dan lembaga yang mengadopsi e-portofolio muncul canggih dan inovatif kepada para kolega dan mahasiswa. E-portfolio tampaknya "inheren” yang baik. Desainer instruksional memberitahu kita bahwa proses membangun sebuah e-portfolio merangsang siswa untuk terlibat dalam pemikiran reflektif. E-portfolio akan menyediakan lembaga akreditasi dengan bukti nyata bahwa siswa mencapai standar berbasis hasil. Lulusan baru akan menggunakan e-portfolio untuk menampilkan kreativitas dan prestasi, terutama untuk memperoleh keunggulan di pasar kerja. Tidak mengherankan, pusat karir penempatan universitas menganggap gerakan e-portfolio sebagai kesempatan untuk menghubungkan hasil akademik untuk tempat kerja.

4. Penelitian yang dilakukan oleh Trent Batson dari The Association for Authentic, Experiential and Evidence-Based Learning (AAEEBL) yang berjudul "12 Important Trends in the ePortfolio Industry for Education and for Learning" tahun 2012. Penelitian ini membahas tentang sebuah portofolio elektronik milik pelajar: sebuah aplikasi berbasis web yang dapat mengupload dan menyimpan setiap jenis file untuk melayani sebagai bukti dalam presentasi dari e-portfolio, seperti untuk kelulusan atau untuk mendapatkan pekerjaan. Dengan demikian catatan elektronik dari prestasi yang dapat terus disortir dan dimusnahkan dari waktu ke waktu. Ini adalah repositori aktif dengan alat manajemen banyak yang dapat menghasilkan presentasi web untuk tujuan tertentu, itu adalah resume pembuat dengan bukti terkait. E-portfolios memungkinkan bergerak dari pendidikan (pendidik sebagai agen aktif) untuk belajar. "Dalam waktu pengetahuan stabil, mengajar, dalam waktu pengetahuan cepat 
berubah, belajar. Ini adalah waktu untuk belajar: Mulai semua pemikiran berdasarkan pertimbangan tentang belajar. Pendidikan menganggap satu set bidang pengetahuan, membatasi penemuan pelajar itu, bidang di mana semua pengetahuan telah ditemukan dan dianalisa, melainkan menganggap siswa akan ditindaklanjuti oleh pendidik bukan mahasiswa / pelajar bertindak atas pengetahuan,. itu menganggap satu jalur untuk semua peserta didik fokus pada belajar, e-portfolios memungkinkan pendidik untuk melakukan, membuka pengalaman belajar.

5. Penelitian yang dilakukan oleh Robert C. Reardon, Jill A. Lumsden, Katie E. Meyer dari NASPA Journal yang berjudul "Developing an E-Portfolio Program: Providing a Comprehensive Tool for Student Development, Reflection, and Integration" pada tahun 2005. Penelitian ini membahas tentang pengembangan portofolio mahasiswa adalah area minat dan aktivitas di banyak kampus. Program e-portfolio memiliki kegiatan yang memungkinkan siswa untuk mempelajari dan mendokumentasikan sembilan keterampilan umum yang berkaitan dengan kehidupan / pengembangan karir, yang kemudian dapat dibagi dengan pengusaha, dosen, dan pengguna dirujuk lainnya. Ini menyediakan kerangka kerja bagi siswa untuk merenungkan dan mengintegrasikan pengalaman penuh pembelajaran. Hasil dari proses evaluasi secara singkat dijelaskan, diikuti dengan peninjauan e-portfolio prestasi program, pekerjaan yang sedang berlangsung, dan kemungkinan masa depan.

6. Penelitian yang dilakukan oleh Rano Kurniawan, Henderi, dan Fitria Nursetianingsih yang berjudul "Penggunaan Ipad Mendukung Pembelajaran Pada Mahasiswa Ilearning" pada tahun 2012 di Perguruan Tinggi Raharja. Penelitian ini membahas tentang iLearning (Integrated Learning) dapat diartikan sebagai metode pembelajaran yang menyeimbangkan antara otak, gerakan dan kecerdasan. iLearning berkaitan dengan 4B (Belajar, Bermain, Bekerja, Berdoa) dan realisasinya menyatu dalam kehidupan sehari-hari. Untuk mendukung keefektifan metode pembelajaran iLearning perlu akan adanya sarana pendukung sebagai standarisasinya. Di dalam iPad terdapat berbagai aplikasi yang mendukung kegiatan belajar, bermain, bekerja, maupun berdoa. Dengan adanya sarana iPad hal ini dapat memudahkan pembelajaran iLearning dan menciptakan integritas yang baik untuk metode pembelajaran. Dengan adanya sarana pendukung ini diharapkan mahasiswa memiliki kemampuan lebih dan selalu up to date dengan perkembangan ilmu pengetahuan dan teknologi, serta berpartisipasi menuangkan ide-ide kreatif untuk pengembangan teknologi ke arah yang lebih maju lagi.

Dari 6(enam) literature review yang ada, telah banyak penelitian mengenai metode pembelajaran menggunakan Sistem Kuliah Portofolio (skup) Mahasiswa berbasis iLearning Media (iMe) pada perguruan tinggi atau yang lainnya. Itulah alasan mengapa penulisan ini membahas hal tersebut. Agar nanti bisa dijadikan acuan sebagai referensi oleh dosen maupun mahasiswa.

\section{PEMECAHAN MASALAH}

Dari permasalahan yang sudah dijelaskan diatas adapun solusi dan cara mengatasi untuk menyelesaikan masalah yang terjadi, dengan adanya media publikasi yang telah diberikan dapat digunakan untuk kegiatan belajar mengajar dengan menggunakan iLearning Media(iMe) Class, selain praktis dan mudah iLearning Media(iMe) Class . pun lebih menghemat biaya, jika pada penulisan documentasi terjadi salah ketik atau kesalahan pada text tersebut maka bisa di edit 
kembali, tidak membuang-buang tinta ataupun kertas, menjadi disiplin waktu dalam mengumpulkan tugas. Sehingga mahasiswa/i lebih semangat dan aktif akan sharing dalam berkomunikasi dan lebih berani mengemukakan sesuatu hal baik tugas maupun pengalaman. Dan kemudian tugas/pengalaman yang telah dibuat akan tersimpan dan tidak akan hilang. iLearning Media(iMe) Class . mempunyai fitur-fitur unik yang di dalamnya terdapat fitur pendukung, selain berisi text mahasiswa/i pun bisa memberikan link dan gambar serta bisa mengganti background yang diinginkan, terdapat juga kalender, Friend List, media social dan recent post. Fitur ini sangat membantu kegiatan pada saat belajar mengajar sehingga mahasiswa/i tidak bosan jika mengunjungi site yang telah dimiliki. Media publikasi iLearning Media(iMe) Class. bukan hanya sekedar untuk kegiatan belajar mengajar didalam kelas namun bisa juga digunakan dalam offsite class. Dengan menggunakan iLearning Media(iMe) Class. dosen dapat mengetahui profil mahasiswa/i secara singkat dan bisa mengetahui secara rinci asiggnment yang telah dibuat oleh mahasiswa/i dengan cara melihat Sistem Kuliah Portofolio (SKUP) mahasiswa tersebut semua tugas yang sudah mahasiswa/i sudah kerjakan sudah sangat mudah untuk dicari .. Dalam Sistem Kuliah Portofolio (SKUP) yang telah dibuat dan telah tersimpan, Sistem Kuliah Portofolio (SKUP) pun bisa dilihat kapan saja. Kemudian Sistem Kuliah Portofolio (SKUP) yang telah tersimpan bisa sebagai acuan untuk semester berikutnya. Semua mahasiswa/i Perguruan Tinggi Raharja dapat menggunakan iLearning Media(iMe) Class . untuk membuat Sistem Kuliah Portofolio (SKUP) . Website tersebut memiliki fasilitas berupa publish dan iPad untuk menjalankan aktivitasnya pada saat mengerjakan tugas. Berikut ini adalah gambaran dalam membuka iLearning Media(iMe) Class agar mahasiswa/i bisa lebih memahaminya.

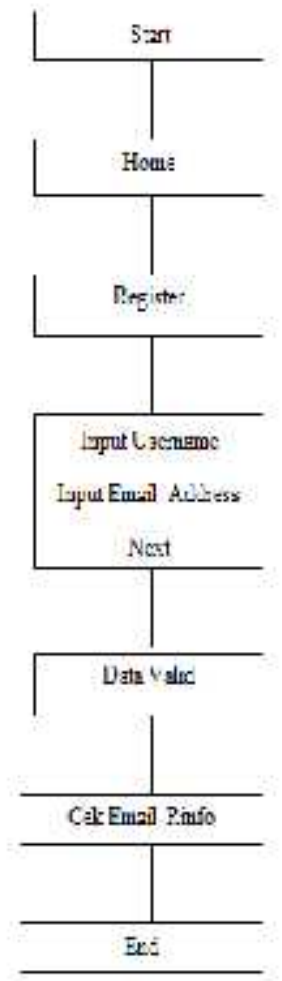

Gambar 3. Register iLearning Media(iMe) 
Gambar diatas merupakan penjabaran dari register iLearning Media(iMe). Setelah mengunjungi ilearning.me di halaman utama terdapat register jika belum mempunyai akun iMe. Pada saat input username dan email address, email yang diinput ialah harus email Rinfo karena bagi pribadi raharja wajib menggunakan Rinfo. Setelah melakukan registrasi kemudian next, kemudian cek email yang merupakan pengiriman untuk user beserta password yang akan digunakan untuk log in iMe.

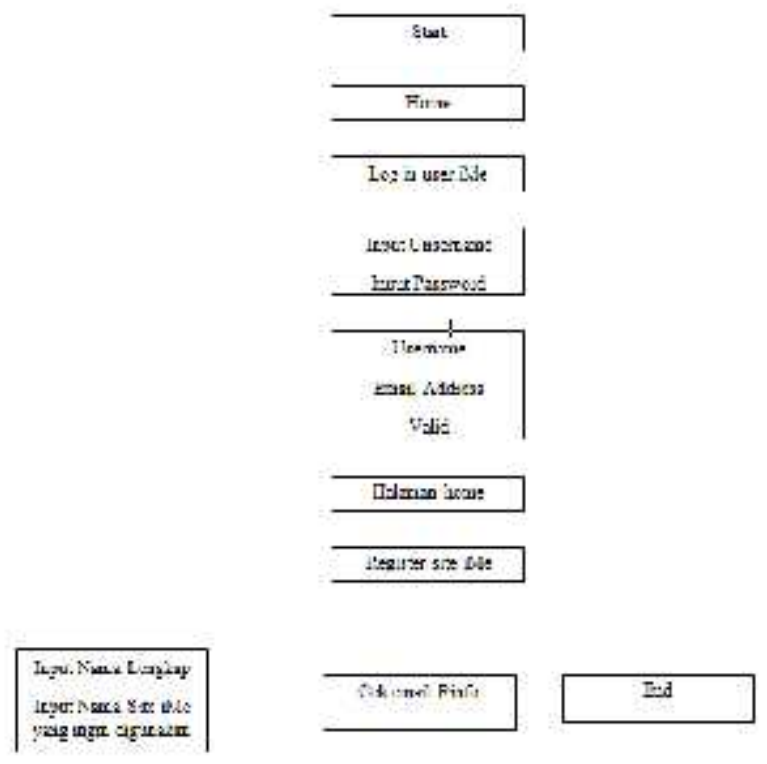

\section{Gambar 4. Register site iMe.}

Gambar diatas menjabarkan proses registrasi site ime. Setelah log in pada site iMe, kemudian pilih registrasi lalu isi registrasi tersebut. Jika sudah lengkap kemudian submit. Lalu cek email Rinfo untuk mengkonfirmasi email dan password yang telah diberikan melalui Rinfo.

Setelah berhasil Register pada iMe, kemudian log in pada site tersebut, bisa langsung mengubah foto profile dan background. Terdapat berbagai macam fitur yang ada di iMe seperti My site, post,pages,comment,Appearence,tools,dsb. Didalam fitur Appearence bisa membuat friend list,media social,dan bisa mengubah tema serta background yang diinginkan dari sebelumnya.
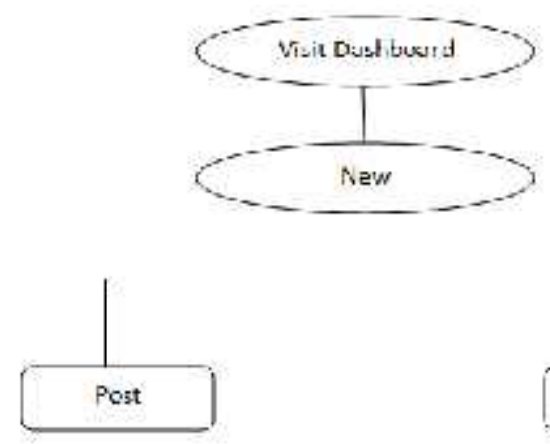

Pages

Gambar 5. Membuat assignment/document 
Dari gambar diatas jika sudah memiliki akun kemudian log in, setelah itu pilih visit dahsboard yang di dalamnya terdapat banyak fitur namun untuk membuat sebuah text, pilih new kemudian ingin membuat post atau pages. Walaupun pages dan post sedikit tidak ada perbedaannya. Dalam pages penulisan dokumentasi lebih rapih dibanding post.

Kegunaan SKUP dalam iLearning Media(iMe) Class antara lain :

- Pembelajaran jarak jauh

- Menghemat biaya

- Individualisme dalam pengerjaannya

- Mendorong mahasiswa/i agar lebih berani mengungkapkan sesuatu hal dan lebih aktif dalam sharing komunikasi dengan teman atau dosen .

\section{IMPLEMENTASI}

Tampilan website iLearning yang memiliki berbagai macam fitur yang dapat digunakan oleh mahasiswa maupun dosen yang terdiri dari:

a. Halaman Utama

website tersebut dapat diakses di luar kampus oleh dosen maupun mahasiswa dengan menuju alamat website http://ilearning.me/

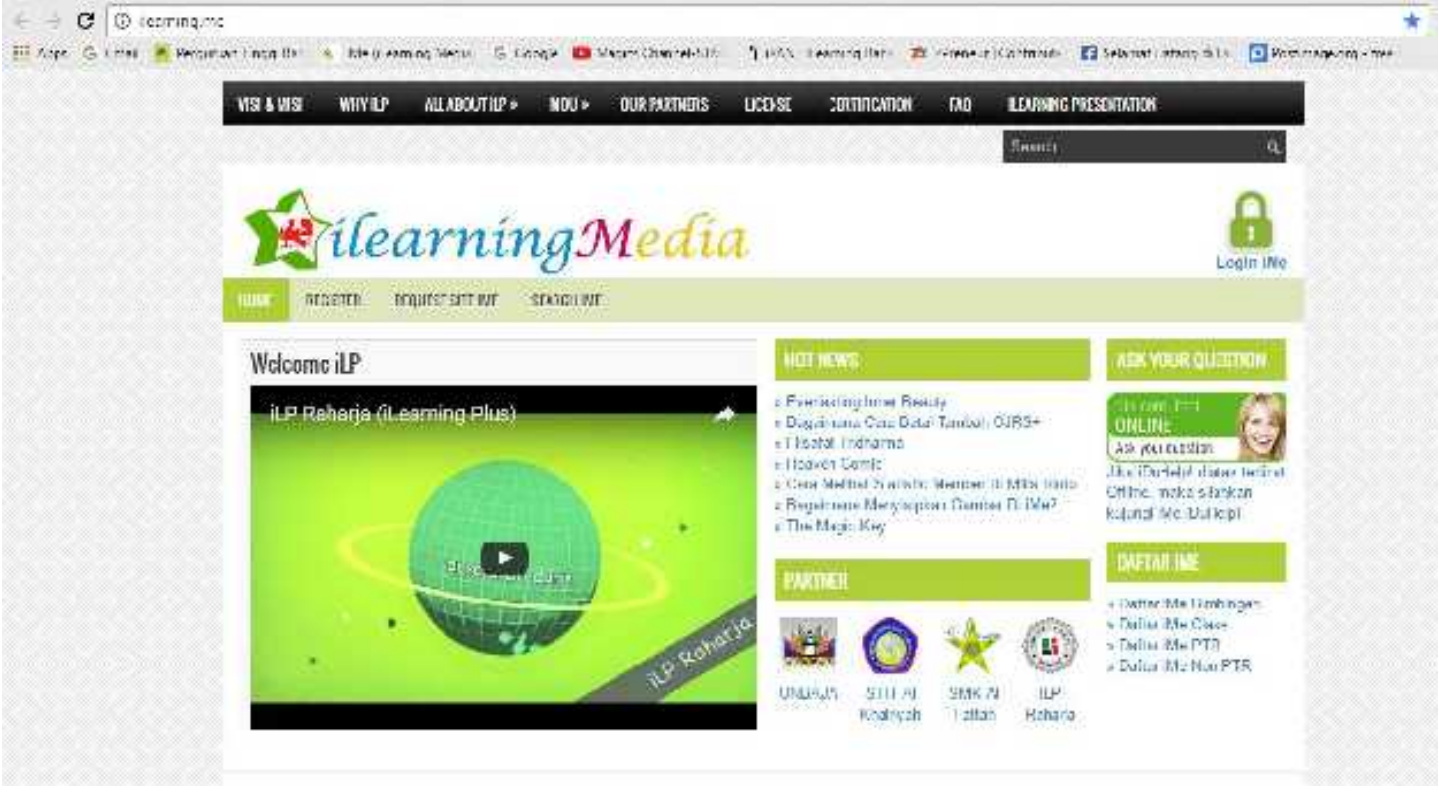

b. Login pada website iLearning.me

Seperti website lainnya adanya login untuk masuk ke dalam website agar bisa memposting suatu artikel. 


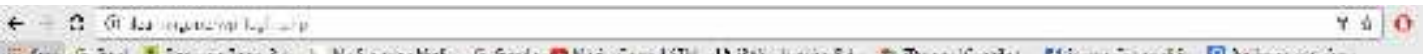

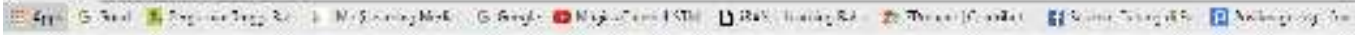

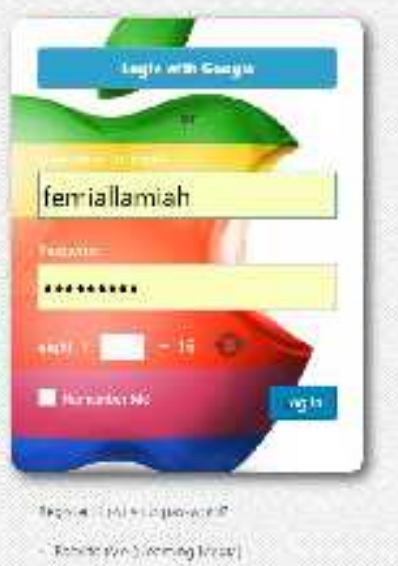

c. Setelah login masuk ke dalam iMe class PL102B

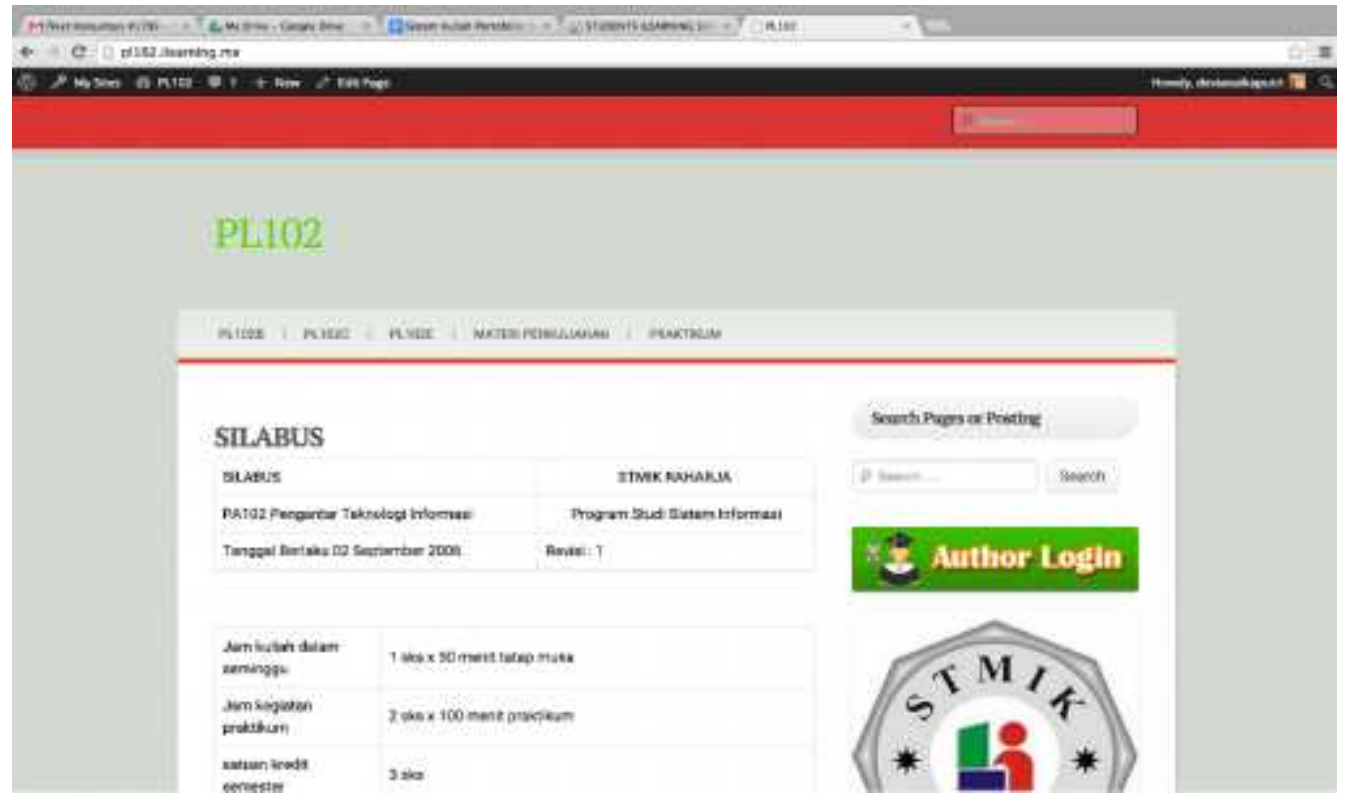

d. Kemudian masuk ke dalam daftar nama mahasiswa yang sudah mengerjakan skup 


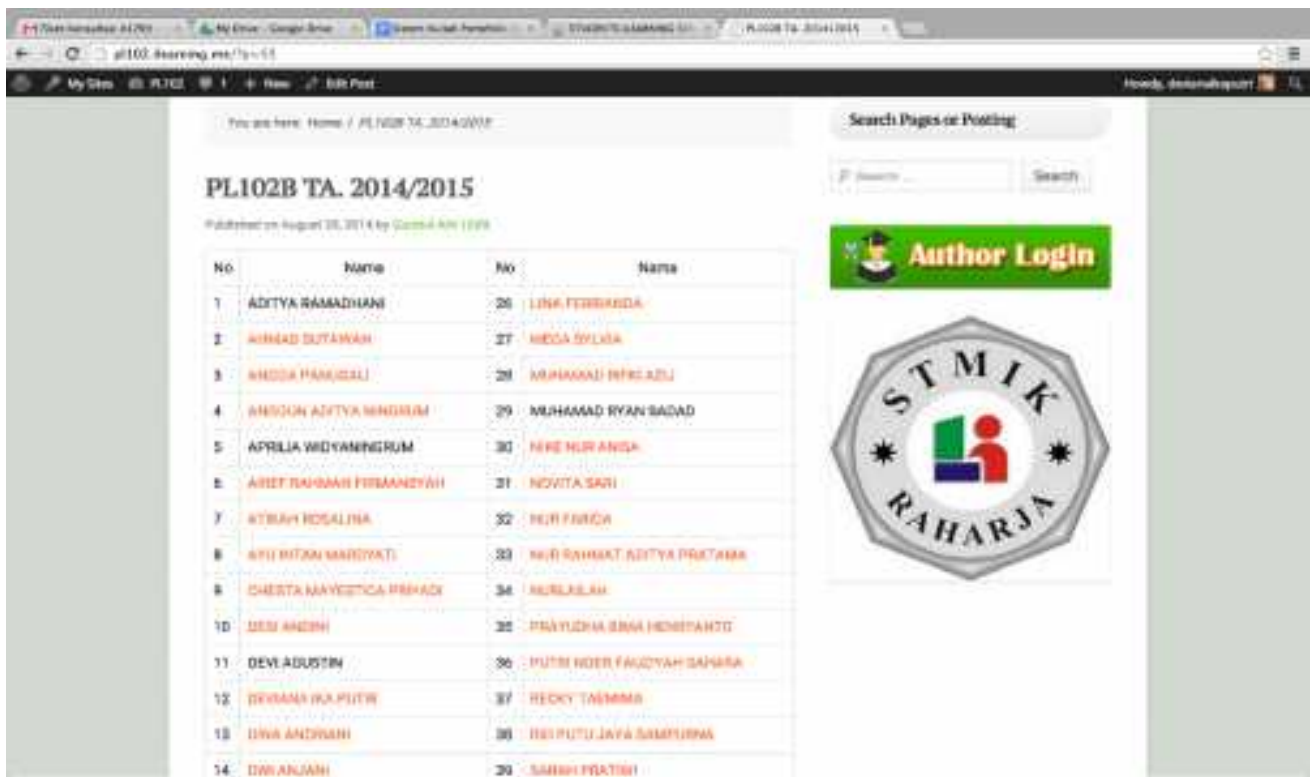

e. Dibawah ini contoh SKUP yang telah di buat

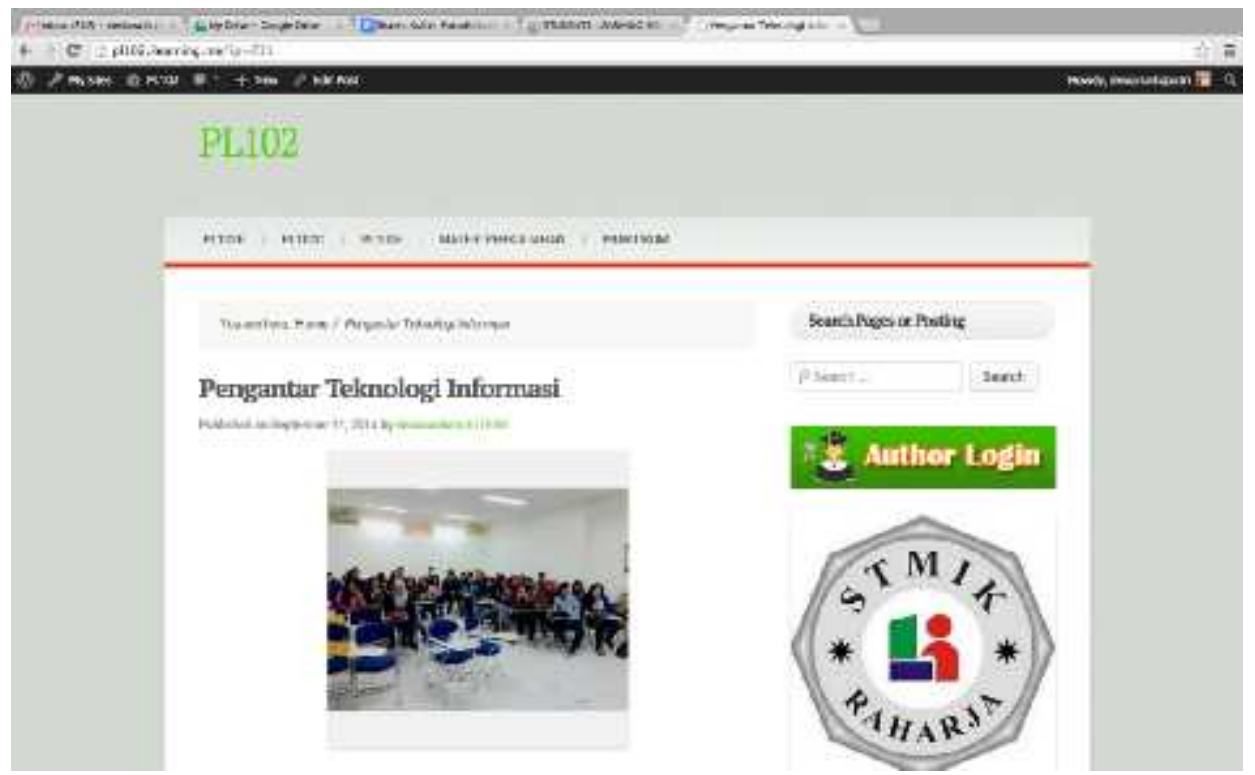




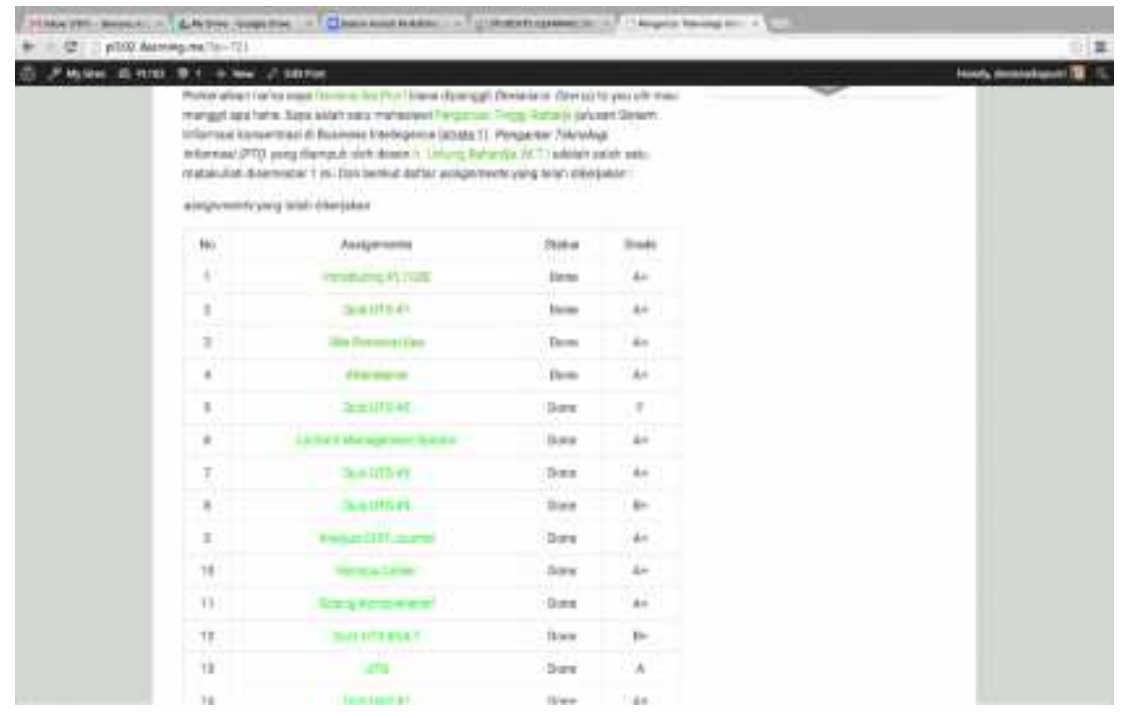

\section{KESIMPULAN}

Dengan adanya iLearning Media(iMe) untuk pribadi Raharja dapat membantu mahasiswa/i lebih aktif dalam sharing berkomunikasi perihal tugas, dan memudahkan mahasiswa/i dalam kegiatan belajar mengajar, namun dengan adanya site iLearning Media(iMe) Class mahasiswa/i lebih efisien dan praktis dalam mengerjakan tugas. Dengan iLearning Media(iMe) Class dosen bisa langsung melihat secara rinci assignment yang telah dibuat, begitu juga para mahasiswa/i bisa melihat site dosen untuk materi pembelajaran. iLearning Media(iMe) Class akan sangat mendukung untuk kegiatan belajar mengajar terutama pada metode iLearning di Perguruan Tinggi Raharja. iMe site pun bisa dilakukan dimana saja pada offsite class. Kemudian banyak berbagai macam tools di iMe yang dapat mendukung pembelajaran seperti menyisipkan gambar pada text tersebut. Dengan adanya media publikasi seperti site iMe mahasiswa/i lebih akurat untuk menyampaikan dan menerima infromasi dari site tersebut secara up to date. Dengan adanya Sistem Kuliah Portofolio (SKUP) didalam iLearning Media(iMe) Class membuat semua tugas perkuliahan mahasiswa/i menjadi lebih tertata rapih Dengan adanya pembelajaran secara online pada Perguruan Tinggi Raharja mahasiswa lebih termotivasi untuk lebih memahami dalam mempublikasikan yang telah dibuat, semakin semangat dalam belajar, bisa dilakukan dimana saja, dan dapat meningkatkan kreativitas mahasiswa/i pada site iLearning Media(iMe) Class yang dimiliki.

\section{DAFTAR PUSTAKA}

[1] Rina, Tri Kartika. 2002, 8 Februari. "Penilaian Portofolio". Kompas.

[2] Sinaradi, F. 2001. "Metode Penilaian Hasil belajar Peserta Didik dengan Portofolio". Dalam P. Suparno, dkk. (peny.). 2001. Menuju Pempelajaran Aktif. Yogyakarta: Penerbitan USD

[3] Surapranata, Sumarna dan Muhammad Hatta. 2006. Penilaian Portofolio: Implementasi Kurikulum 2004. Bandung: PT Remaja Rosdakarya. 